\title{
Research on the Strategies of Collaborative Innovation of the Emerging Industries in Suzhou City
}

\author{
Jie ZHAO
}

Economics and Management Department, Changshu Institute Of Technology, Jiangsu Changshu, China

\begin{abstract}
Under the new economic environment, Industry-University-Research(IUR)collaborative innovation not only helps knowledge flow within regional innovation system, it but also is the basic approach to promote independent innovation capability of enterprises and technical ability of regional industry. The internal and external environment factors lead to the lack of innovation are discovered by analyzing the status of IUR collaborative innovation of emerging industry in Suzhou, and the strategies to cope with existing problems are presented, which include establishing a "four wheel drive" structure mode of governmentindustry-university-research, building a sound IUR collaborative innovation base, strengthening the construction of soft environment of IUR collaborative innovation and so on. The research results will provide a powerful theoretical and practical supports for the development of IUR collaborative innovation of emerging industries in Suzhou City.
\end{abstract}

KEYWORD: Emerging industry; IUR platform; Collaborative innovation

1 THE THEORETICAL FOUNDATION OF INDUSTRY-UNIVERSITY-RESEARCH COLLABORATION INNOVATION

\subsection{Emerging Industry}

As to the definition of emerging industry, the views of most scholars are identical: emerging industry refers to the new industry or industry groups appeared in an area in a certain period of time due to the invention and application of new achievements in scientific research and new technology or the development of new market [1].

\subsection{The Connotation of IUR Collaboration Innovation}

IUR Collaboration Innovation refers to the three basic subjects of industry, university and research institution, supported by the government, intermediary service of science and technology, financial institutions and other related service organization, put into their respective advantages in resources and technical ability to develop technology jointly [3]. The purpose of enterprises to implement collaborative innovation is to promote the industrialization of scientific and technological achievements through IUR innovation chain(such as technology layer), promote the industrial clusters innovation network spreading from a single enterprise to the combination of IUR, promote the changing of innovation rate of industry cluster and life cycle of industrial technology and thus most likely to shorten innovation costs and improve innovation capacity through collaboration. For universities and research institutions, their strong innovation ability and focus can make up the lack of the innovation capacity and technology resource of enterprises.

\section{THE PROBLEMS OF THE DEVELOPMENT OF IUR COLLABORATION INNOVATION IN SUZHOU CITY}

\subsection{Deficiency of innovation fund of company}

Because the emerging industry is a special industry and a new things in the stage of upgrading and transformation in China, its cultivation and development need to invest a lot of innovation funds. The R \& D funds of a company are often limited and need to get money from capital market. But there are many factors such as underdeveloped external financing guarantee institutions, unsound capital market, high risk and high instability and inadequate understanding of bank about company that hindered the company to obtain funds from capital market. Thus it is very common that an innovation enterprise is lack of funds. Lack of 
innovative funding restricted the further development of enterprises, and thus adversely affected the incubating of industrial technology achievements and industrialization of emerging industries.

\subsection{Loose organization mode of enterprises, low- end and homogenization of technical cooperation}

According to statistic data, among 10 districts of Suzhou City by the end of the 3 quarter of 2014, there are 9 districts that their under construction projects in the field of new materials and high-end manufacturing exceed $50 \%$ of total projects under construction, 8 districts the output value of new materials ranked in top 3 in emerging industries and 7 districts the high-end manufacturing output value ranked in top 2 [4]. It shows that the development of emerging industry of Suzhou mainly concentrated in the field of new materials and high-end manufacturing. This homogenization phenomenon is not conducive to the formation and development of regional characteristic industry.

In 2013, the foreign enterprises of Suzhou realized $79 \%$ output value of total high-tech industries, of which $58 \%$ are computer and office equipment manufacturing, electronics and communications equipment manufacturing [2]. It indicates that the part of enterprises in emerging industries of Suzhou only make some simple expanded reproduction relying on existing advantages of production factors, instead of taking risk to develop and transform science achievements.

Furthermore, besides the large and medium sized enterprises or groups in the urban, which had established close cooperation entity and technological innovation network alliance with universities and research institutes, most companies in other regions, especially SMEs, had only established a linear "point to point" mode IUR collaborative innovation. This kind of collaboration has a loose structure and a low integration. It is hard to meet the needs of improving the ability of independent innovation of enterprises and great innovation of industry technology under new conditions.

\subsection{Less enthusiasm of universities to take part in the IUR collaborative innovation}

At present, most universities and research institutes involved in collaborative innovation projects are only responsible for technology and are not involved in the application and commercialization of outcome. This situation makes universities not to attach too much importance to the transformation of achievements. In addition, the teachers are not allowed to apply for patent for invention or utility model relied on the IUR collaborative innovation projects. This also makes the enthusiasm of university teachers to participate the IUR collaborative innovation projects affected greatly.

\section{MEASURES TO OPTIMIZE COLLABORATIVE INNOVATION OF EMERGING INDUSTRIES IN SUZHOU CITY}

\subsection{Constructing "four wheel drive" development mode of Government-Industry-University- Enterprise (GIUE)}

In order to make the role of enterprises more outstanding in the level of micro operation, we present a "four wheel drive" development mode of government, industry, research institution (university) and enterprise[6,7]. In this mode, the four bodies are not dependant. They intercross each other, interact each other and interconnect each other. The mode is shown in Figure 1.

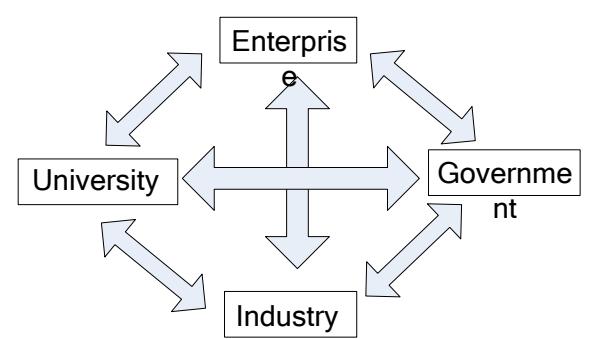

Fig.1 "four wheel drive" development mode

In Figure 1, the interaction relationships of four bodies are as follows:

1) Industry-Research institution(University)

The cooperation of industry and university is the core part of GIUE collaborative innovation. The demands of enterprises mainly come from market, policy, capital, technology and talent, and the universities' demands come from the discipline development, upgrading the level of scientific research and personnel training. To cooperate successfully, both sides must find cooperation points and cooperation ways that are in line with their core target. The supports university gives to industry mainly focus on strategic planning, technology innovation and talent. On the contrary, the supports of industry are financial support and achievements transformation. In addition, the ultimate goal of university and enterprise is different. Therefore, how to find the common interests will become the key of the coordinated development.

2) Industry-Government

The nature of the enterprise is to create profits, and the economic function of government is to make up the defect of the market. In the process of innovation economy development, enterprises are 
the main body of technical innovation, while the government should maintain the market order, antimonopoly, anti pollution and follow the sustainable development principle through making industry policy. Through correcting the externalities of market, the government will create a sound atmosphere for innovation, paving the way for the healthy development of innovation economy.

3) Enterprise-Industry

The industry or industry cluster is the basic structure form from the perspective of the innovation system. Industry not only represents the industry group-a highly relevant product or business communities or clusters, but also represents the industry chain-constituted by different technology links and interconnected each other. Enterprise will gradually grow up to industry by the measures of gathering and guiding, and the industry will comprehensively support the development of the enterprise by creating a suitable environment.

4) Research institution (university)-Government

Research institution (university) and government should get a consensus view about GIUE cooperation. On the one hand, research institution (university) should broaden the view of technology to strive for more innovation resources; on the other hand, the government should provide financial and policy support to promote the development of GIUE collaborative innovation. The cooperation of university and enterprise not only brings opportunities, but also has a lot of uncertainty. Therefore, research institutions (universities) hope that the government could participate in the process of innovation, so as to reduce the risk of innovation and improve innovation cooperation service level.

5) Research institution (university)-Industry

In current, knowledge has become innovation capital. Under this condition, University's role is no longer confined to the traditional personnel training and project cooperation. It should also participate in the industrial development planning and lead the innovation development so as to convert knowledge into capital and promote the economic development. In the process of knowledge capitalization, knowledge production has become a part of the market to a certain extent. Therefore, all kinds of emerging industries would make full use of the congenital advantage of university, vigorously promote the development of GIUE collaborative innovation.

6) Government-Industry

Industrial cluster is an important model of the formation of the regional innovation system, and regional innovation ability is related to the industrial clusters advantages of the region. The development situation of our country's government-led industries shown that the technological knowledge flow promoted by government had made a different agglomeration degrees of different industries. The government promoted the industries' clustering and rapidly increased the regional innovation capability through establishing the CMC Development Zone, Therefore, the region under the condition of industrial cluster has the innovation advantage.

\subsection{Building a new sound base of IUR collaborative innovation for emerging industries}

IUR cooperation is an effective way to enhance regional technological innovation capability. The IUR cooperative mode can divide into four types such as technology transfer, commissioned research, united Development and building entity jointly according to the experience from abroad. No matter which kind of mode, a IUR collaborative innovation base is needed. The emerging industry cooperative innovation base usually has three stages of development, The schematic diagram is shown in figure 2 .

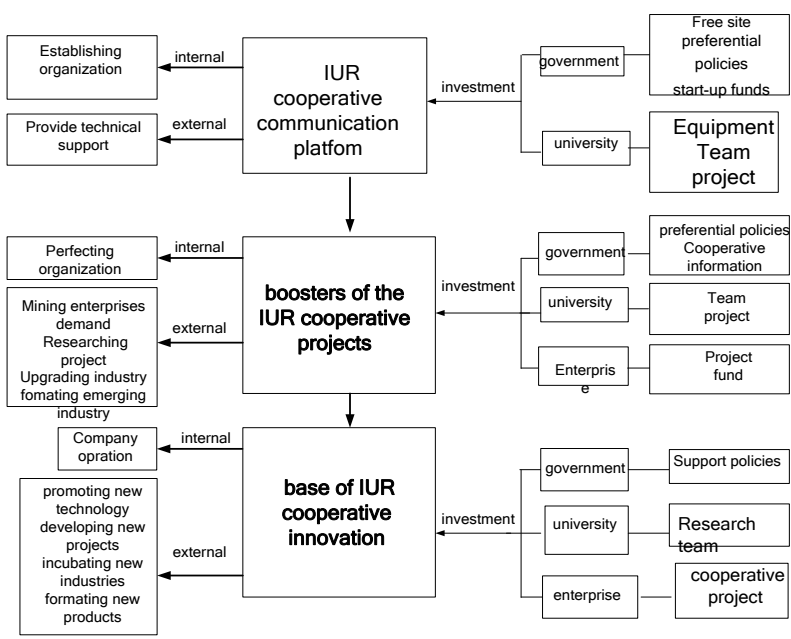

Fig.2 Three stages of Suzhou IUR cooperative innovation

The main tasks of the base are: in internal, to integrate organization better and realize the company operation; in external, to further promote new technologies, new project development and truly become a base of school enterprise cooperation. From the investment point of view, the government mainly provides some preferential policies for the steady development of innovative base; the scientific research institution (university) should invest a large amount of research effort to ensure that the projects under research and to be researched would carry out smoothly; the cooperative enterprises need to provide active supports for cooperative projects. 


\subsection{Strengthening the soft environment construction of emerging industry IUR collaborative innovation}

\subsubsection{Strengthening the construction of policy and law system}

According to the related theory of management, the government is not only the guardian of the market economy, but also the protector of the science and technology innovation. At present environment of market economy, the development direction of emerging industry needs governmental guidelines according to the regional characteristics and industrial cluster resources. This makes the the external environment such as laws, tax and policy, that related to IUR collaborative innovation, very important and cannot be missed. Therefore, in view of the current situation of the development of IUR innovation, the main measures should be strengthened are: to develop new type of $\mathrm{R} \& \mathrm{D}$ institutions, to formulate practical strategy of regional science and technology development, to implement feasible support policies of finance, tax and the invention reward.

\subsubsection{Encouraging and guiding the high-end and heterogeneity development of emerging industries}

In view of the homogenization and low-end situation of the emerging industry products at present, the government should adjust the industrial structure, encourage and guide the heterogeneity and high-end research emerging industry collaborative innovation projects to be produced and implemented, so as to lay a solid foundation for the development of emerging industries and make Suzhou a stronger competitiveness in the process of industry transformation and upgrading.

\subsubsection{Strengthening the protection of intellectual property}

In order to achieve the aim of intellectual property protection, technology assessment and technology pricing mechanism of innovation base should be established. The technology assessment indicators and assessment scheme based on market laws should also be developed so as to determine the value of technology output of innovation base. On the basis of this, a reasonable living space will be given to innovation base through formulating government suggested price and government's macro control. At the same time, the government should strictly protect the achievement of innovation base according to the existing laws and regulations so as to encourage application of invention patent.

\subsubsection{Strengthening the construction of science and technology intermediary service system}

In view of the current backward situation of the science and technology intermediary service, government can establish a cooperative information network for the whole society, regularly collecting supply and demand information of technical problems of enterprises and technological achievements of universities. In addition, the government also should focus on the cultivation and development of science and technology intermediary service institutions such as assessment advisory body, occupation training institutions and all kinds of technical, economic, legal and other aspects of the advisory services, building a more comprehensive platform of exchange and service.

\section{REFERENCES}

[1] Zhang Xuewen. 2013. Industry--university collaborative innovation from open science perspective--Institutional logic, contractual governance and social welfare(in Chinese), Studies in Science of Science. 4:617-622.

[2] Jian Lirong. 2012. A Study of the Typical UniversityIndustry Coordinated Innovation Mechanism in the World (in Chinese). Journal of Higher Education Management. 9:6-10.

[3] Zhang Qinpeng. 2014. Research on the government guiding mechanism of the coordination innovation (in Chinese). Science \& Technology Progress and Policy. 3:1-5.

[4] Wang Jinfu. 2013. Research on Collaborative Innovation Mechanism (in Chinese). Science \& Technology Progress and Policy. 16:1-6.

[5] Wang Hongli. 2011. Stusy on University Park Innovation service system from the perspective of University-Industry and Research(in Chinese). Science and Technology Management Research. 9:24-28.

[6] Zhao Liangen. 2008. Research on the construction of Pudong regional IUR cooperative innovation mechanism (in Chinese). Journal of China Executive Leadership Academy Pudong. 3:105-111.

[7] Chen Yi. 2013. Theoretical Model of Knowledge Collaborative of Production, Teaching and Research(in Chinese). Sci-tech Innovation and Productivity. 10:10-14. 